\title{
Heidegger e a superação da crise dos fundamentos: antecedentes para a proposição de uma ontologia fundamental
}

\section{Heidegger and the overcoming of the ground's crisis: antecedents to the proposal of a fundamental ontology}

\section{Bruno Martins Machado*}

Doutorando em Filosofia, Universidade Estadual de Campinas - UNICAMP, Campinas, SP, Brasil

\begin{abstract}
RESUMO
O presente texto tem como objetivo mostrar que o conceito heideggeriano de Dasein, tal como foi apresentado em Ser e Tempo, surgiu como uma solução à pergunta pelos fundamentos do conhecimento. A discussão dos fundamentos foi um tema que emergiu com a crise das matemáticas no século XIX e motivou o trabalho de muitos estudiosos de diversas áreas. Dentre grandes nomes que tentaram encontrar um fundamento para o conhecimento, destaca-se Husserl que efetivamente abriu as portas para recolocar o homem no centro da discussão da questão do conhecimento. Portanto, teve um papel imprescindível no desenvolvimento do percurso tomado por Heidegger. É sob essa perspectiva que o panorama geral do artigo parte da apresentação do momento que eclodiu a crise das matemáticas. Em seguida, aponta como Husserl tenta resolver o problema de um fundamento seguro para o conhecimento desenvolvendo a noção de um eu transcendental. Por fim, apresenta como o Dasein emerge como resposta inicial à pergunta pelo Ser.
\end{abstract}

Palavras-chave: Dasein, Fundamentos, Heidegger, Husserl, Matemáticas.

\begin{abstract}
This paper objectives to show that the heideggerian concept of Dasein (as it was presented in Being and Time) emerged as a solution to the question for the knowledge's ground. The quarrel of the grounds emerged with the crisis of the mathematical in XIX century and it motivated the work of many scholars of diverse areas. Amongst great names that had tried to find a ground for the knowledge Husserl is distinguished because he effectively opened the doors to put the human being in the center of the discussion of the knowledge question. Therefore, it had an essential paper in the development of the passage taken for Heidegger. It is under this perspective that the general panorama of this paper has left of the presentation of the moment that came out the crisis of the mathematical. After that, it points as Husserl tries to decide the problem of a safe ground for the knowledge developing the transcendental notion of ego. Finally, it presents the emergence of the Dasein as a reply to the question for the Being.
\end{abstract}

Keywords: Dasein, Fundamentals, Heidegger, Husserl, Mathematics. 
O presente texto tem como propósito contextualizar dentro da tradição ocidental a preocupação de Martin Heidegger em buscar uma ontologia fundamental. Para tanto, partimos da idéia de que a ontologia fundamental é a resposta de Heidegger à exigência de uma fundamentação segura para todo e qualquer conhecimento. Pela notória complexidade do assunto, não temos a pretensão de exaurir o tema por completo, porém nos limitamos a uma tentativa (já bastante ousada) de apresentar considerações que indiquem a profundidade das raízes apresentadas por Heidegger na introdução de Ser e Tempo ${ }^{1}$.

$\mathrm{Na}$ tentativa de atender ao objetivo acima destacado dividimos o texto em três partes: (i) Na primeira, apresentaremos aspectos do momento que instalou a crise das matemáticas no século XIX, enfatizando o papel fundamental desta ciência frente a todos os campos de conhecimento. (ii) $\mathrm{Na}$ segunda, apontamos como a reflexão de Edmund Husserl se configura como uma exigência na busca por um fundamento rigoroso. E também, como esse fundamento já é direcionado para o homem. (iii) Por fim, na terceira, apoiando-nos em trechos dos dois primeiros parágrafos de ST, indicaremos como a questão é uma preocupação fundamental dentro desta obra tão importante da história da filosofia.

\section{Da crise das Matemáticas à necessidade de uma ciência dos fundamentos}

\subsection{As Matemáticas: estrutura elementar para a construção de conhecimento}

Primeiramente interessa-nos saber o porquê de partir das matemáticas?

A resposta está no papel que a matemática assumiu perante as ciências e a própria filosofia. Por volta do século XVI, a matemática se tornou para as ciências modernas um fundamento inabalável sobre o qual todo o conhecimento deveria ser erguido. Com essa medida vimos a física se separar da filosofia e se consolidar como uma disciplina capaz de mensurar, quantificar, determinar intervalos de tempo, de espaço - tudo sob a proposta de compreender, verificar e prever os eventos existentes no mundo.

Sob tais parâmetros, a matemática se tornou a grande aliada da física. Vale ressaltar que quando a física se separou da filosofia natural (meio de compreensão do mundo desde a Antiguidade), ela abriu caminho não apenas para as ciências naturais, mas também para as ciências do espírito. Com o aprofundamento das ciências modernas cada aspecto da realidade passou a ser estudado em termos matemáticos: os eventos deveriam ser descritos segundo fórmulas e leis cujos fundamentos deveriam proceder de equações matemáticas. 
Esse movimento que deu origem à física moderna foi depositário do filósofo Galileu Galilei.

\begin{abstract}
Devemos a Galileu o moderno espírito científico na forma de uma harmonia entre experiência e teoria. Ele fundou a mecânica dos corpos em queda livre, lançou os fundamentos da mecânica em geral, e sobre esses fundamentos mais tarde Newton foi capaz de construir uma ciência. (...) Do ponto de vista histórico são interessantes as colocações de Galileu que mostram que ele captou a idéia de equipotência de conjuntos infinitos, um ponto fundamental na teoria dos conjuntos de Cantor no século XIX, com tantas implicações importantes no desenvolvimento da análise moderna. (EVES, 2004, p. 355)
\end{abstract}

Todas essas considerações acima e as principais idéias de Galilei sobre a dinâmica estão no seu Discorsi e Dimonstrazioni Matematiche intorno a Due Nuove Scienze, publicado em 1638. Ele "considerava a mecânica como ciência por excelência" (ALES BELLO, 2004, p. 38). Para estudar com precisão o movimento, Galilei julgou necessário interpretá-lo utilizando o auxílio de fórmulas matemáticas. ${ }^{2}$ Portanto, a imagem da natureza que a nova ciência nos apresentava estava radicalmente ligada à matemática.

O uso da matemática para estruturar uma cosmologia cada vez mais se aprofundou na Modernidade. Os modelos matemáticos que interpretavam a natureza não apenas valiam no âmbito macroscópico, mas também, no âmbito microscópico. Assim, a partir dos modernos, o estudo da natureza cada vez mais se distanciava de uma análise filosófica tornando-se um conhecimento específico da física e da matemática.

Lembremos também que foi Galilei, juntamente com Copérnico e Kleper os pensadores que revolucionaram toda a compreensão que o homem possuía de si mesmo. Eles foram os responsáveis pelo fim do antropocentrismo. Ao destituir o homem do centro do universo, abriram-se as possibilidades para novas interpretações que deveriam explicar o mundo sem necessariamente terem que passar por uma leitura antropocêntrica. Enquanto modelo mais notável desse movimento, a física foi acompanhada por todas as outras ciências.

Desse momento em diante, a matemática se tornou peça imprescindível para qualquer ciência que almejasse rigor, precisão e previsão. Definitivamente, a mecânica era a prova de que o mundo era constituído a partir de fundamentos matemáticos. Newton pode ser considerado como o grande exemplo do ápice dessa perspectiva interpretativa. As leis do movimento e da refração, bem como, toda a mecânica clássica têm sua fundamentação erguida sobre a matemática. 


\title{
1.2. A crise dos fundamentos das Matemáticas.
}

Mas, mesmo com espaço consagrado no âmbito do conhecimento, do meio para o fim do século XIX as Matemáticas levaram um grande golpe. Elas foram o palco de uma forte crise que abalou não apenas as próprias matemáticas, mas também, todas as ciências (naturais e humanas). Foi uma crise de dimensões tão amplas que obrigou a uma reestruturação no campo das ciências e abriu portas para a teoria da relatividade e para a física quântica.

Dentro dos propósitos deste texto, meu interesse se limitará a apontar alguns aspectos que delineiam os contornos desse momento tão importante na história do pensamento Ocidental. Portanto, não pretendo aqui desenvolver exaustivamente as etapas dessa crise.

Destarte, na primeira metade do século XIX, ocorreram dois acontecimentos notáveis que mudariam todas as perspectivas matemáticas desse momento em diante. Foram eles: (i) "a descoberta, perto de 1829, de uma geometria autoconsciente, diferente da geometria usual de Euclides" (EVES, 2004, p. 539); (ii) "a descoberta, em 1843, de uma álgebra diferente da álgebra familiar dos números reais" (EVES, 2004, p. 539).

A consequência da descoberta de geometrias não-euclidianas foi a liberação da geometria de seus moldes tradicionais. Caiu por terra todo um pensamento que defendia ser possível apenas a existência de uma geometria que correspondesse ao mundo efetivo. Nesse sentido, para os matemáticos, os postulados da geometria transformaram-se em meras hipóteses cuja verdade ou falsidade física não era de seu interesse.

\begin{abstract}
As características de "auto-evidência" e "veracidade" atribuídas aos postulados desde os gregos deixaram de ser consideradas pelos matemáticos. Com a possibilidade de inventar geometrias puramente "artificiais", tornou-se evidente que o espaço físico devia ser visto como um conceito empírico derivado de nossas experiências exteriores e que os postulados da geometria, formulados para descrever o espaço físico, são simplesmente expressões dessas experiências, como as leis de uma ciência física. O postulado de Euclides, por exemplo, na medida em que tenta interpretar o espaço real, revela ter o mesmo tipo de validade que a lei de queda livre dos corpos de Galileu; isto é, ambos são leis que decorrem da observação e ambos são suscetíveis de verificação dentro dos limites do erro experimental. (EVES, 2004, p. 544)
\end{abstract}

Assim, o pensamento de que o mundo poderia ser compreendido segundo sua tradução em números começou a perder força. Desmoronou também a hipótese kantiana de que os postulados da geometria euclidiana, considerados por Kant juízos a priori, eram imprescindíveis para qualquer raciocínio sobre o espaço. Por outro 
lado, surgiram novas hipóteses para interpretar os problemas: abriuse espaço para as Weltanschaung, para as geometrias analítica, progetiva, diferencial e $\mathrm{N}$-dimensional, também, para uma nova lógica que ultrapassava a aristotélica.

A imagem era então de uma completa revolução no pensamento provocado pela geometria. Se alguns postulados haviam sido derrubados causando alguns problemas, a confusão piora inda mais com a emergência das estruturas algébricas. No início do século XIX, a álgebra era reduzida apenas à aritmética simbólica (é o mesmo modelo que conhecemos na escola secundária atualmente). Isso significa que ao invés de utilizar números específicos $(1,2,400,35$ ect.) para resolver problemas como se faz em aritmética, a álgebra emprega letras, que representam tais números $(a, b, c \text {, etc. })^{3}$.

Em 1843, o irlandês Willian Rowan Hamilton, levado por algumas considerações físicas, concebeu um raciocínio algébrico em que tornava inválida a propriedade comutativa da multiplicação ${ }^{4}$. Ao lado de Hamilton, outros dois matemáticos, Grassman e Cayley abriram espaço para a álgebra abstrata que não só enfraqueceu e suprimiu alguns postulados algébricos tradicionais, como também substituiu outros por construções mais consistentes. O resultado efetivo dessas descobertas foi um número muito alto de sistemas a serem pesquisados: conjuntos, grupos, semigrupos, monóides, anéis, domínios de integridade etc. (EVES, 2004, p. 553). Com a invenção de novos campos, a proporção de estudos aumentou vertiginosamente. Hoje ela é tão grande que a álgebra é considerada "a chave mestra da matemática".

Curiosamente, um dos efeitos colaterais da libertação da álgebra foi abrir o caminho para a chamada "arimetização da análise". Esse movimento buscava, sobretudo, por um fim aos cálculos impróprios, pois cada vez mais os professores se deparavam com erros provenientes de aplicação das operações. Em poucas palavras, os matemáticos estavam preocupados pois um entendimento precário de uma teoria poderia levar a aplicação precária, cega e ilógica dessa teoria. Eves (2004) nos apresenta a situação:

Tangidos pela aplicabilidade imensa do assunto, e carecendo de um entendimento real de seus fundamentos, os matemáticos manipulavam os processos analíticos de uma maneira quase cega, muitas vezes guiados apenas pela intuição. O resultado só poderia ser uma acumulação de absurdos, até que, como reação natural ao emprego desordenado do intuicionismo e do formalismo, alguns matemáticos conscienciosos se sentiram na obrigação de tentar a difícil tarefa de estabelecer uma fundamentação rigorosa para a análise. (p. 609-610)

Em busca desse entendimento mais profundo dos fundamentos da análise encontramos o professor alemão Karl Weierstrass. 
Weiertrass defendeu um programa no qual o próprio sistema de números reais, antes de mais nada, fosse tornado rigoroso para que assim tudo que dele decorresse na análise inspirasse segurança. Esse notável programa, conhecido como aritmetização da análise, revelou-se difícil e intrincado, mas acabou se concretizando através de Weiertrass e seus seguidores, e hoje a análise pode ser deduzida logicamente de um conjunto de postulados que caracterizam o sistema dos números reais. (EVES, 2004, p. 611)

Um imenso campo de incertezas e um terreno aberto para amplas investigações - assim se configurava o cenário das matemáticas no fim do século XIX. Era necessário progredir nos estudos. Mas era necessário evitar ao máximo qualquer digressão que levasse o pesquisador para longe dos fundamentos, pois o resultado do distanciamento dos fundamentos lógicos e teóricos era quase sempre o erro.

\section{Husserl e a descoberta de novos fundamentos}

\subsection{A busca por uma ciência fundamental}

Essa ausência de fundamentos na matemática levou a corridas desenfreadas por todos os lados das ciências. É nesse período que a teoria lingüística moderna ganha força, o vitalismo ganha espaço e o positivismo é tomado como uma grande proposta de salvação das ciências. É o grande momento das Weltanschaung: tudo pode ser lido como uma visão de mundo (a filosofia, a matemática, a física, a teologia - todas são interpretações).

De fato, se formos pensar que não havia um lastro firme sobre o qual seria possível balizar todo conhecimento, verificamos que o momento era desesperador. Talvez, mais preocupante ainda para Edmund Husserl (1859-1938). Um estudante que entrou no meio acadêmico em 1876 e se doutorou em matemática em 1882 com a tese "Beiträge zur Theorie der Variationsrechnung". Uma tese em cálculo diferencial orientada por Leopold Könisberger ${ }^{5}$, um dos discípulos de Weierstrass. A preocupação com os fundamentos acompanhou Husserl por toda sua vida, não por acaso aconteceu sua aproximação com Weierstrass. Como indica Moran (2005):

Weierstrass, por sua vez, foi inspirador, provocando no jovem Husserl o "etos do labor científico". Suas leituras sobre teoria das funções estimulou o interesse de Husserl sobre os fundamentos das matemáticas de uma maneira tal que ele posteriormente escreveu que esperava fazer pela filosofia o que Weierstrass fez pela aritmética, a saber, colocou-a sobre uma única fundação. (p. 16) 
Assim, podemos atestar que a questão dos fundamentos estava presente em quase todos os seus cursos e livros. Olhando para o momento filosófico vivido por Husserl torna-se ainda mais evidente o objetivo de laborar por uma ciência dos fundamentos.

No fim do século XIX, na Alemanha, a sensação era de que os grandes sistemas filosóficos haviam sido esgotados. Exemplo de figuras que padeceram desse esgotamento: Hegel e Schopenhauer. Outros grandes nomes do pensamento Ocidental, tais como Nietzsche e Freud ainda não tinham suas construções consolidadas. Portanto, eles estavam fora do ensino na academia. O clima vivido pelos estudantes alemães era de que faltava algo. Havia uma espécie de vazio quanto ao grande nome que seria a nova referência tanto das ciências, quanto da filosofia. Em voga existia uma forte crença nas ciências positivas e nas descobertas da psicologia.

Nesse terreno a fenomenologia encontrou um solo propício para o seu florescimento. É indiscutível o papel que o movimento fenomenológico ocupou na história do Ocidente como uma das grandes correntes filosóficas do século XX. Na Alemanha, em um período que antecedeu a Primeira Grande Guerra, Edmund Husserl buscou desenvolver um método investigativo que, segundo ele, elevaria a filosofia à condição de ciência rigorosa. Sua pesquisa conquistou cada vez mais adeptos e mesmo com toda onda antisemita, levada adiante pelo Partido Nacional Socialista que posteriormente imprimiu sua prática como política de Estado, durante o período da Segunda Grande Guerra Husserl não parou seus trabalhos. Tampouco sua influência no campo acadêmico estagnou.

O filósofo morreu em 1938, deixando um grande número de escritos e adeptos, o que favoreceu um fervoroso reestabelecimento da corrente fenomenológica logo depois da Segunda Grande Guerra. Pouco tempo depois de sua deposição da reitoria, o conjunto de seus escritos foi levado de Freiburg para Louvain, com o propósito de não serem destruídos pelos nazistas. Até hoje, seus textos e manuscritos encontram-se na Bélgica, nos Arquivos Husserl.

Efetivamente, o ponto de partida da fenomenologia husserliana foram as reflexões sobre as matemáticas e a lógica. Sua busca inicial girava em torno da questão: Como se constituem os objetos matemáticos? Só a opção pela consciência the pareceu a solução para o problema. O fenômeno seria a estrutura elementar para pensar esse mundo de objetos. Aqui percebemos a influência de Franz Brentano com a noção de consciência intencional que apontava a relação consciênciaobjeto como o aspecto básico do fenômeno.

Mesmo bastante criticado por outros pensadores, a exemplo de Frege que o acusava de estar promovendo um reducionismo da aritmética à psicologia, Husserl havia optado por um novo método de análise. Um método que exigia uma concepção de subjetividade diferente, capaz de indicar objetos para além do conteúdo psíquico real. Essa 
preocupação inicial constitui nos escritos husserlianos um percurso que se estende das primeiras obras até a Sexta Investigação Lógica. Ao fim das Investigações Lógicas, a fenomenologia não se aproximava nem de um idealismo, nem de um realismo, contudo, algumas questões emergiram. Os desdobramentos dessas questões remeteram a uma enorme crise de fundamentos que desembocou nas reflexões transcendentais. Por mais que prefigurem um método de análise dos fenômenos e a partir deles uma perspectiva de construção de conhecimento, as Investigações não tinham solucionado duas grandes questões: (i) Como se dá a relação da consciência com um eu ou sujeito (puro)? (ii) Qual o estatuto do mundo real ou "natural"?

\begin{abstract}
Era possível tratar do "fluxo dos vividos" e da sua unidade, como Husserl fazia na Quinta Investigação, sem os referir a um eu puro, não empírico, como seu fundamento? Era possível, numa teoria do conhecimento, tratar a transcendência da coisa, que apenas se dá sempre em "esboços", sem colocar, ao mesmo tempo, o problema geral da transcendência ou do ser do mundo, relativamente ao ser da consciência? (KELKEL; SCHÉRER, 1982, p. 34)
\end{abstract}

\title{
2.2. O Eu como fundamento: retomada da meditação cartesiana
}

Logo após as Investigações Lógicas, Husserl caiu em um ceticismo e recomeçou sua busca por fundamentos rigorosos e seguros para amparar a filosofia e o conhecimento. As conferências de 1907 refletem este momento, elas foram publicadas com o título Idéia da Fenomenologia.

Husserl precisava de um método filosófico radical que estivesse à altura de um programa completo de uma filosofia de cunho rigorosamente científico. A busca empreendida por Husserl pretendia solucionar o problema que a realidade do conhecimento transcendente nos colocava. Seu grande insight foi observar o modo como Descartes concebeu o ego cogito como ponto arquimediano para toda elaboração de conhecimento. O ego cogito era, para ele, o "domínio último e apoditicamente certo sobre o qual deve ser fundada qualquer filosofia radical" (HUSSERL, 2000, p. 30)

Esse recurso a Descartes foi explorado por Husserl já no primeiro volume de Idéias Diretrizes para a Fenomenologia. Posteriormente, foi retomado na introdução e na primeira meditação da sua obra Meditações Cartesianas. Vejamos como Husserl apresentou seu problema nas Meditações:

As ciências positivas em nada cuidaram destas Meditações que, todavia, Ihes deviam fornecer um fundamento racional absoluto. É verdade que depois de se terem brilhantemente desenvolvido durante três séculos, estas ciências hoje 
sentem-se entravadas no seu progresso pela obscuridade que reina nos seus próprios fundamentos. Mas mesmo nos pontos em que tentam renovar esses fundamentos, nem sequer sonham em remeter para as Meditações de Descartes. (HUSSERL, 1987, p. 12)

Aqui Husserl chamou a atenção expressamente para a importância da reflexão cartesiana e, ao mesmo tempo, criticou todas as ciências por não terem tomado o pensamento como fundamento seguro para reflexão. A importância de Descartes foi que ele conseguiu promover um retorno ao eu puro, precisamente, o eu das cogitationes puras. Esse retorno foi feito através do método da dúvida. Certamente, Descartes representava para Husserl um avanço no modo como se conhecia o mundo. Sob tais aspectos Descartes foi revolucionário ao tratar o campo transcendental a partir do ego:

\begin{abstract}
Descartes inaugura um tipo novo de filosofia. Com ele a filosofia muda totalmente de comportamento e passa radicalmente do objetivismo ingênuo para o subjetivismo transcendental, subjetivismo que, não obstante tentativas sem cessar renovadas, sempre insuficientes, parece tender todavia para uma forma definitiva. (HUSSERL, 1987, p. 13)
\end{abstract}

Em termos husserlianos essa era a exigência que a filosofia cartesiana nos impôs. Portanto, era imprescindível continuar a reflexão pelos fundamentos a partir das Meditações Metafísicas. De fato, Husserl foi preciso no modo como caracterizou a sua maneira de se apropriar do texto cartesiano: ele propôs "ressuscitar as Meditações cartesianas, não certamente para adotar na sua totalidade, mas para desvendar antes do mais a significação profunda de um retorno radical ao ego cogito puro" (HUSSERL, 1987, p. 13). Esse percurso consolidou a fenomenologia transcendental.

Como atestou Ricoeur (1998), a primeira tarefa das Meditações Cartesianas era buscar situar na história da filosofia o propósito transcendental da fenomenologia. Isso Husserl fez para mostrar que uma investigação rigorosa, seja ela científica ou filosófica, não poderia ser ingênua tal como estavam sendo as ciências positivas da natureza, as matemáticas, a lógica etc. Portanto, a fenomenologia era defendida pelo seu criador como o passo necessário para desenvolver qualquer proposta de conhecimento verdadeiro.

O segundo propósito das Meditações era resgatar a radicalização do cogito cartesiano. Somente resgatando a radicalização do cogito é que a filosofia poderia avançar. Isso era uma tarefa complexa, pois, ao fim das Meditações sobre Filosofia Primeira, nem mesmo o próprio Descartes foi capaz de manter-se fiel ao seu empreendimento. É nesse sentido que Ricoeur (1998) pontuou: "As Meditações Cartesianas sugerem essa idéia que a história da filosofia tem um 
sentido na medida em que caminha em direção a superação de sua própria história por um progresso no sentido do verdadeiro começo (commencement)." (p. 75) Um começo que pode ser pensado a partir da pergunta pelo o sentido da radicalização do cogito.

Analisando mais de perto o Descartes de Husserl, encontramos traços de um cartesianismo observado do ponto de vista de um momento neokantiano, ou seja, "a grandeza de Descartes segundo Husserl é de ter feito o projeto de uma filosofia que fosse ao mesmo tempo uma ciência e o fundamento de todas as ciências no sistema de uma ciência universal. Em verdade, o cogito é o sujeito transcendental." (RICOEUR, 1998, p. 76) Entretanto, para Husserl, Descartes se afastou do próprio radicalismo pois a dúvida metódica cartesiana deveria encerrar qualquer idéia que desse margem para pensar em uma exterioridade independente do sujeito. O problema cartesiano foi insistir em uma corrente dedutiva que para afirmar a efetividade do mundo se consolidou da seguinte maneira: cogito, res cogitans, existência de Deus, existência da natureza objetiva.

A existência de Deus se mostrou nas Meditações sobre Filosofia Primeira como um elemento imprescindível na cadeia construtiva da extrapolação do conhecimento do homem para o mundo, pois somente Deus garantiria a validade de todos os seres. Deus, portanto, garantiria a existência do mundo como objeto real diante do cogito. Na elaboração cartesiana, a idéia de um Deus perfeito é imprescindível para afirmar a existência verdadeira do mundo.

A radicalização proposta por Husserl foi um descaminho da filosofia cartesiana. Ela não operava com os fundamentos: cogito, Deus. Husserl utilizou o ceticismo cartesiano para dar força a sua busca por fundamentos e quando encontrou o cogito fez com que ele se sustentasse por si só até o último momento da investigação.

A melhor introdução ao sentido das Meditações Cartesianas
de Husserl é talvez essa destruição do sentido original do
cartesianismo, segundo a qual o cogito é ele mesmo um ser,
situado entre o ser e o nada, um ser insignificante, habitado
e invadido por uma idéia que o faz explodir: a idéia de
infinito; esta idéia, que tem do ser como eu que a pensa,
provoca um deslocamento do centro de gravidade da
subjetividade em direção ao ser infinito. (RICOEUR, 1998, p.
76-77)

A filosofia transcendental assumia, assim, uma característica peculiar, a saber, ela era uma egologia. O ser não serviria para dar um significado de realidade ao objeto, a realidade tinha seu sustentáculo no próprio ego cogito e este nele mesmo. O fundamento de todo conhecimento se afirmaria então como o sujeito transcendental.

\section{Heidegger: uma reviravolta em direção ao fundamento. 3.1. A pergunta pelo Ser}


O esforço de Husserl foi grandioso, tornou possível a concepção do método fenomenológico e a recondução do homem a um dos pólos indispensáveis à investigação. Entretanto, restavam ainda algumas dúvidas: Estaria respondida a questão sobre o fundamento de um conhecimento seguro? Seria a redução transcendental capaz de chegar ao termo último acerca do qual todas as essências dependeriam? A fenomenologia transcendental poderia ser concebida como uma ontologia universal verdadeira?

Para Martin Heidegger a resposta a todas três perguntas é negativa.

Heidegger entra para a história da filosofia como um dos pensadores mais consistentes e geniais de todo ocidente. Suas obras têm um rigor filosófico, um alcance teórico e uma profundidade conceitual admiráveis. Dentre suas mais marcantes preocupações destaca-se a perspectiva de colocar em um eixo não tecnicizado as reflexões filosóficas. Por isso, uma das marcas de seus escritos é a desconstrução.

\begin{abstract}
A desconstrução praticada por Heidegger percorre, portanto, uma trajetória circular muito especial: ela sai do presente tecnicizado, volta à origem grega do primeiro começo do pensamento do ser e vai poeticamente para o outro começo desse mesmo pensamento. (LOPARIC, 2004, p. 30)
\end{abstract}

Na esteira dessa circularidade, caso observemos a Introdução de Ser e Tempo, percebemos que nela foi encaminhado o projeto de colocação da pergunta pelos fundamentos a partir do Ser. Seu título geral é "Explicitação da pergunta que interroga pelo sentido do Ser" e está dividida em dois capítulos. No primeiro são apresentadas as condições da apresentação e da estruturação da pergunta pelo Ser. No segundo, Heidegger põe a discussão nos trilhos dos termos que vão dar sentido ao Ser, sem deixar de lado aquilo que fora explicitado no capítulo anterior.

A Introdução desta notável obra emerge pela necessidade de esclarecer e encaminhar a resposta à pergunta mote de ST. Se considerarmos a questão inicial:

Temos hoje uma resposta à pergunta que interroga por aquilo que queremos dizer com a palavra "ente"? De maneira alguma. Assim é objeto, pois, fazer novamente a pergunta que interroga o sentido do ser. Então, estamos hoje ao menos perplexos por não compreender a expressão "ser"? De maneira alguma. (HEIDEGGER, 1951, p. 2)

Percebemos que, Heidegger iniciou seu escrito nos apresentando a aporia que rondava a temática do Ser. Pretendendo transitar por esse terreno, em Ser e Tempo, o filósofo elegeu a pergunta pelo Ser como a questão filosófica por excelência. Aquela que uma vez solucionada 
alicerçaria toda estrutura do conhecimento. Heidegger estaria assim propondo uma redescoberta dos fundamentos do conhecimento no ocidente a partir da pergunta pelo sentido do Ser.

Com Heidegger, a pergunta pelo fundamento, que fora tão buscada pelos matemáticos do século XIX, assimilada e ampliada por Husserl, ganhou um extenso horizonte não reducionista e extremamente rigoroso. Podemos perceber não apenas o rigor, mas também a riqueza e a abrangência desse "novo" fundamento já nos 2 parágrafos iniciais de ST. São textos em que Heidegger, ao seu modo, também procurou atender à antiga preocupação de seu orientador Edmund Husserl, qual seja, evidenciar o fundamento sobre o qual todo conhecimento poderia ser edificado.

Então, ao abrirmos ST lemos no §1 a afirmação de que a pergunta pelo ser estava esquecida na filosofia desde Platão e Aristóteles. Ela deve, portanto, ser retomada como "pergunta expressa de uma investigação efetiva" (ST, §1) que procura fugir de preconceitos que circulam a noção de ser desde a Antiguidade. Tais preconceitos são as noções de: (i) Ser enquanto entidade como conceito mais geral. (ii) Ser enquanto conceito que não possui definição devido a sua generalidade. (iii) Ser enquanto conceito "óbvio", que por si mesmo carrega sua compreensão (selbstverständlich).

Esses três preconceitos com ampla profusão enorme em toda tradição filosófica justificam que a pergunta pelo Ser (Frage nach dem Sein) seja retomada. Com um detalhe seminal: não devemos cometer os mesmos deslizes da tradição que reduziu o Ser a entidade do ente, isto é, concebeu o Ser como um gênero supremo do ente. Pelo contrário, devemos encontrar outro caminho para estruturar e responder a pergunta pelo Ser.

\subsection{Da estrutura da pergunta pelo Ser à fundamentação}

Assim, o ponto de partida de toda investigação convergiria para a própria pergunta do Ser (Seinsfrage). Esta, por sua vez deve obedecer à estrutura geral do perguntar. Como nos apresentou Heidegger:

Todo perguntar é um buscar. Todo buscar tem sua direção prévia advindo do buscado. Perguntar é buscar conhecedor do ente em seu o que e seu modo de ser [Dass- und Sosein]. O buscar conhecedor pode tornar-se um investigar ou por em liberdade e determinar aquilo que pelo que pergunta. Enquanto pergunta por... [Fragen nach...] o perguntar tem seu perguntado [Gefragtes]. Todo perguntar por é de algum modo perguntar a... [Anfragen bei...]. Além daquilo que se pergunta, ao perguntar é inerente um perguntado pela pergunta [Befragtes]. Na pergunta investigadora, quer dizer, especificamente teórica, o perguntado deve ser determinado e traduzido em conceitos. Como aquilo a que se intenciona, no perguntado reside aquilo que se pergunta [das Erfragte] 
isto em que o perguntar chega a sua meta. (HEIDEGGER, $1951, \S 2)$

Observando o trecho acima, é imprescindível para apontarmos em seu todo a estrutura formal da pergunta específica do Ser (Seinsfrage), pois só ela pode ser traduzida como fundamento da pergunta pelo Ser (Frage nach dem Sein). Destarte, destaca-se: (i) O Dasein como ente perguntador (Frager). (ii) O Ser é o perguntado (Gefragtes). (iii) O perguntado pela pergunta (Befragtes) é o ente ele mesmo. Enquanto compreendido pelo ente que entende Ser, o Dasein é o ente de quem se pergunta (wobei es angefragt wird).

No sentido do aspecto iii foi que Heidegger consolidou o Dasein como termo fundamental. Na sequência investigativa determinada pela estrutura da pergunta do ser, o Dasein assumiria um duplo papel: (iv) ele é o primeiro que pergunta e também o primeiramente interrogado. É por isso que o Erfragtes (aquilo que se pergunta) é direcionado ao sentido do Ser enquanto tal em sua totalidade (überhaupt).

Assim Heidegger apresentou a viravolta do fundamento, a saber, ele atestou que a estrutura da questão em geral só poderia ser revelada em seu fundamento caso se observasse primeiramente a essência do Dasein (ente finito que entende ser). Em poucas palavras, o perguntado pela pergunta do ser é o próprio ente questionador, o Dasein, que se coloca na posição de interrogado primeiro pelo seu movimento questionador e segundo pela sua posição factídica (relativo a factum).

Desenvolver a pergunta que interroga pelo Ser, segundo isto, quer dizer: fazer "ver através" de um ente - o que pergunta - sobre o ponto de vista de seu ser. O perguntar desta pergunta está, enquanto modo de ser de um ente, ele mesmo determinado essencialmente por aquilo pelo que se pergunta nele - pelo Ser. Este ente que somos em cada caso nós mesmos e que tem entre outros traços a possibilidade de ser do perguntar, nós o designamos com o termo Dasein. (HEIDEGGER, 1951, §02)

Por ser um ente que possui uma compreensão prévia do Ser e que por isso se interroga sobre os outros entes e sobre si mesmo, o Dasein desde sempre entende ser já no comportamento cotidiano para com os outros entes. É a partir desse momento que ele se lança na busca da compreensão do Ser realizando a pergunta do Ser. É por tal razão que a sequência imediata de ST, depois dos dois primeiros parágrafos, exige "a prévia e adequada análise de um ente (o Dasein) tendo como alvo o seu ser. 
Heidegger, assim, já nos primeiros parágrafos de ST, firma seu ponto arquimediano sobre a analítica do Dasein. Para Husserl a tentativa de Heidegger se mostra pouco científica:

[Husserl] tinha certeza de que o esforço principal de toda sua vida filosófica consistira na tentativa de tornar para sempre impossível o sistema de filosofia do tipo que vinha sendo elaborado por Heidegger, caracterizado - as palavras são de Husserl - por uma "genial não-cientificidade. (LOPARIC, 2004, p. 12)

Para outros, o ponto de partida heideggeriano se apresentava apenas como um "círculo da prova".

Heidegger rebateu a acusação defendendo:

Na pergunta que interroga pelo sentido do Ser não há um círculo na prova, mas sim um notável retorno daquilo que se pergunta (o Ser) ao perguntar mesmo como modo de ser de um ente. Ao sentido mais peculiar da pergunta que interroga pelo Ser é inerente o Ser, o perguntar essencialmente alcançado por aquilo de que se pergunta. Mas este quer apenas dizer: o ente do tipo do Dasein tem uma referência possivelmente até assinalada - à pergunta mesma que interroga pelo Ser. (HEIDEGGER, 1951, §02)

Para os fins do presente texto vale ressaltar que o Dasein se apresenta como o ponto de partida de onde qualquer pergunta pode ser anunciada. Principalmente porque o Dasein pode colocar a pergunta fundamental que é a pergunta pelo Ser. Portanto, o Dasein oferece o caminho para a fundamentação necessária para a produção de conhecimento. O conhecimento em qualquer campo dever ser precedido por dois aspectos necessários: (i) A estruturação formal da questão do Ser, que evidencia a precedência (Vorrang) da questão ôntica e ontológica sobre qualquer outra forma investigativa provenientes de qualquer outro campo de conhecimento; (ii) A precedência do Dasein como ente que deve ser investigado na totalidade de seu ser, em relação aos demais entes. Esses dois temas serão desenvolvidos respectivamente nos parágrafos 3 e 4 de ST.

Ao tomar o Dasein como aquele ente que pode realizar a pergunta pelo Ser, Heidegger radicaliza ainda mais alguns aspectos buscados por Husserl ao conceber o sujeito transcendental. Dasein se justifica por si mesmo, e o passo dado por Heidegger frente a Husserl foi atribuir a esse ente (o Dasein), o estatuto basilar em uma investigação ontológica. Com o Dasein não é mais necessária a abstração até um campo transcendental para encontrar o fundamento, pois o próprio ato de perguntar já faz do Dasein o caminho para toda investigação. Assim, o Dasein recoloca o homem no centro da estruturação do conhecimento. 
Na busca por fundamentos, partindo de uma crise que começou nas matemáticas do século XIX, tanto Husserl quanto Heidegger empreenderam um movimento crítico de conotação monumental: eles foram cruciais para o nascimento da Fenomenologia enquanto corrente de pensamento. Portanto, sem eles a ampliação do horizonte do movimento crítico tão presente entre os modernos estaria comprometida.

Sobre a importância do movimento fenomenológico Gadamer afirma: "ela [Fenomenologia] buscou evitar toda construção não certificada e sujeitar ao exame crítico domínios inquestionados das teorias filosóficas." (GADAMER, 2004, p. 07). Com essa dimensão crítica, a Fenomenologia quis se afastar dos prejuízos que até hoje caminham junto à filosofia.

\section{Referências Bibliográficas}

ALES BELLO, A. Fenomenologia e ciências humanas. Trad. Maria Massimi; Miguel Mahfoud. Bauru: EDUSC. 2004.

EVES, H. I ntrodução à história da matemática. Trad.: Hygino $\mathrm{H}$. Domingues. Campinas: Editora da Unicamp. 2004.

GADAMER, H. G. The phenomenological movement (1963). In.: Phenomenology: critical concepts in philosophy. Ed. MORAN, D.; EMBREE, L. E. London; New York: Routledge. 2004. p. 05-43.

HEIDEGGER, M. El ser e el tiempo. Pró. y trad. José Gaos. México: Fondo de Cultura Econômica. 1951.

$\overline{1} \overline{9} \overline{\bar{C}}-2005$.

Gesamtausgabe. Frankfurt am Main : Vittorio Klostermann.

HUSSERL, E. A I déia da fenomenologia. Trad. Artur Mourão. Lisboa: Edições 70. 2000.

Meditações cartesianas. Trad. Maria G. Lopes e Souza. Porto: Editora Rés. 1987.

KELKEL, A. L.; SCHÉRER, R. Husserl. Trad.: Joaquim João Coelho Rosa. Lisboa: Edições 70. 1982.

LOPARIC, Z. Heidegger. Rio de Janeiro: Jorge Zahar. 2004.

MORAN, D. Edmund Husserl. Cambridge; Malden: Polity Press. 2005.

RICOEUR, P. Etude sur les «Méditations Cartésiennes » de Husserl. In : A L'École de la phénomenologie. 4ạ ed. Paris: Librairie Philosophique J. Vrin. 1998. p. 187-232.

Endereço para correspondência

Bruno Martins Machado 
Universidade Estadual de Campinas, Instituto de Filosofia e Ciências Humanas, Rua Sérgio Buarque de Holanda, CEP 13081-970, Campinas- SP, Brasil

Endereço eletrônico: brmach@hotmail.com

Recebido em: 04/08/2009

Aceito para publicação em: 25/03/2010

Acompanhamento do processo editorial: Ana Maria Lopez de Calvo Feijoo

\section{Notas}

* Psicólogo pela Universidade Federal de Sergipe - UFS; Mestre em Filosofia pela Universidade Estadual de Campinas - Unicamp.

${ }^{1}$ Doravante utilizaremos para nos referimos a Ser e Tempo a abreviação ST.

${ }^{2} \mathrm{~A}$ idéia de utilizar fórmulas matemáticas para definir o movimento tem origem platônica. "[...] O mundo das I déias é o mundo da verdade, o qual é um mundo geométrico; sendo que as coisas do mundo físico são formadas conforme figuras geométricas. Há uma carta de Galileu muito famosa na qual escreve: 'O grande livro da natureza é escrito em caracteres matemáticos'. Quais são esses caracteres? Triângulos, quadrados, a geometria. Nisto repousam as raízes filosóficas platônicas da posição de Galileo." (ALES BELLO, 2004, p. 38-39)

${ }^{3}$ Antes da revolução na álgebra, acreditava-se que existia uma estrutura algébrica formada pelas cinco propriedades abaixo e seus desdobramentos:

Se $a, b$ e c indicam inteiros positivos arbitrários, tem-se:

1. $a+b=b+a$ (propriedade comutativa da adição).

2. $a \cdot b=b \cdot a$ (propriedade comutativa da multiplicação).

3. $(a+b)+c=a+(b+c)$ (propriedade associativa da adição).

4. (a . b) . c =a . (b. c) (propriedade associativa da multiplicação).

5. a. $(b+c)=(a \cdot b)+(a \cdot c)$ (propriedade distribuitiva da multiplicação em relação à adição).

${ }^{4}$ Sobre dedução da quebra dessa propriedade Cf. EVES, 2004. p. 548-551.

${ }^{5}$ Weierstrass indicou um de seus discípulos para formalizar a orientação de Husserl porque por questões acadêmicas o matemático estava impossibilitado de orientar doutoramentos. 